\title{
New Identification Method for Backlash of Gear Transmission Systems
}

\author{
Jie Zhang ${ }^{1,2}$, Heng Zhang ${ }^{1,2}$, Xinxin Xiao ${ }^{1,2^{*}}$ \\ 1. Institute of Mechanics, Chinese Academy of Sciences \\ 2. School of Engineering Science, University of Chinese Academy of Sciences \\ Beijing, China \\ *xiaoxinxin@imech.ac.cn(Corresponding author)
}

\begin{abstract}
To achieve precise identification of backlash in gear systems, a new identification method is proposed on the basis of hysteresis backlash model and the describing function method. A Discrete Fourier Transform is used to extract the fundamental components from the system output digital. Then the relationship between the phase angle of describing function and that of the fundamental components is utilized to identify backlash. A sinusoidal excitation with small amplitude and low frequency is applied as the system input, in order to reduce the impact and collision between meshing teeth, highlight the hysteresis effect and improve identification accuracy. A gear transmission system with backlash is considered as a numerical model, simulation results reveal this method can achieve precise backlash identification. Numerical tests with multi-group excitations are conducted, the results reveal that the effects of the selection of amplitude and frequency of excitation on the accuracy of the identification method can't be ignored.
\end{abstract}

Keywords-Gear transmission; Backlash identification; Hysteresis model; Describing Function

\section{INTRODUCTION}

Backlash exists in gear pairs inherently due to lubrication requirement, manufacturing or installation errors [1], which inevitably influences the accuracy, stability and operating life of the system [2 3]. Under the influences of temperature, abrasion and loads, gear backlash becomes time-varying and difficult to measure directly in most cases. Therefore, it's necessary to conduct research on gear backlash identification according to measurable information. Accurate identification of backlash can provide critical foundation and guarantee for modeling and precision control of the system [4].

Backlash identification methods are generally developed based on dead-zone model and hysteresis model [5]. There are several types of dead zone model, including the typical dead zone model without considering damping [6], elastic dead zone model that considers damping effects [7], two modified dead zone models of elasticity and collision are considered, and an approximate dead zone model which are established based on polynomial fitting [1]. Founded on elastic dead zone model, Nordin [7] and Tjahjowidodo [6] proposed a strategy with identification of $0.05 \mathrm{rad}$ and $0.12 \mathrm{rad}$ backlash respectively. Lagerberg et al. put forward a method in terms of modified dead zone model [8]. Mazzini studied the identification of robot arm system with multi-backlash [9]. Until now, the dead zone model is still not unified, which limits its application to backlash identification. There are also backlash identification studies using hysteresis model. Bai proposed identification algorithms for the system with hard input nonlinearities [10]. Tarng et al. put forward techniques for the backlash identification and compensation for computer numerically controlled machining centers [11]. In a comprehensive view, the accuracy of backlash identification needs to be improved to meet the accuracy requirements of precision instruments and equipment with gear train.

A new identification method is proposed based on the hysteresis model and its describing function, proper excitation signal is selected to reduce collision effects of transmission process and make full use of the relationship between the lag phase and backlash in quasi-static transmission. The modeling of gear transmission system with backlash demonstrates the validity and accuracy of the identification method. This work can provide support for the accurate modeling and control design for geared mechanical system with backlash.

\section{IDENTIFICATION METHOD OF BACKLASH}

\section{A. Hysteresis model and its describing function}

There will be a significant hysteresis phenomenon between the input and output when the geared mechanical system with backlash is in a quasi-static state. As shown in Fig. 1(a), there is a constant delay between the rotating angle of drive and driven gears when the gears engaged. The interaction between drive and driven gears disappears as the rotation of drive gear is reversed and driven gear separates from drive gear, during this period the drive gear will pass through the backlash and collide with the driven gear on the back side, as illustrated in Fig. 1(b), there is a delay between the rotation angle of drive and driven gears in the contact-separation-contact process which is caused by backlash [12 13].

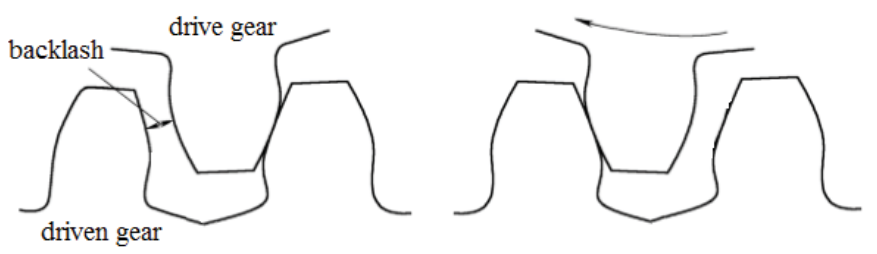

(a) Delay between the rotation angle of drive and driven gears 


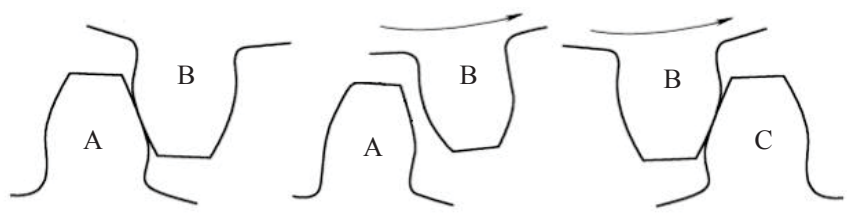

(b) Contact-separation-contact process

Fig. 1. Sketch map of contact status of gear backlash.

The hysteresis backlash model can be established based on the hysteresis phenomenon of the geared mechanical system with backlash. This model assumes that the driven gear keep static in the contact-separation-contact process. This assumption can be satisfied in two cases: high damping of load side or low rotation inertia and damping of drive side. The hysteresis model commendably describes the quasi-static transmission process of the geared mechanical system.

The describing function method has been demonstrated to be an effective tool used for nonlinear system stability analysis [12 13]. This method considers that the fundamental wave of the output of the nonlinear system that satisfies certain conditions is approximate to the system output with the sinusoidal excitation. It's applicable to most nonlinear systems [12 13]. With sinusoidal signal as the input of the system with gear backlash, the system outputs are shown in (1) and Fig. 2.

$$
\begin{aligned}
& \theta_{\text {out }}=\left\{\begin{array}{lc}
k\left(\theta_{\text {in }}-\delta\right) & 0 \leq \omega t \leq \frac{\pi}{2} \\
k\left(\theta_{m}-\delta\right) & \frac{\pi}{2} \leq \omega t \leq \pi-\beta \\
k\left(\theta_{\text {in }}+\delta\right) & \pi-\beta \leq \omega t \leq \pi
\end{array}\right. \\
& \beta=\sin ^{-1}\left(\frac{\theta_{m}-2 \delta}{\theta_{m}}\right)
\end{aligned}
$$

where $2 \delta$ is the backlash angle, $\theta_{m}$ and $\omega$ are the amplitude and frequency of excitation, respectively, $k$ is the slope of the output characteristics.

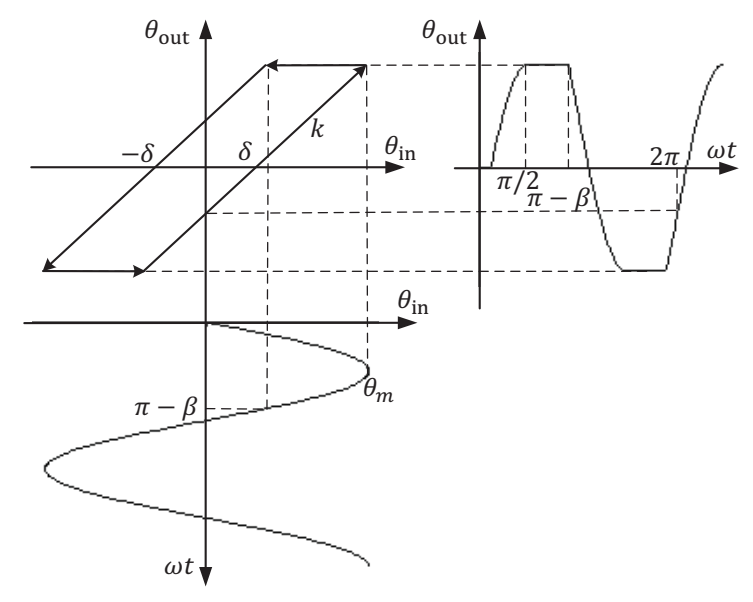

Fig. 2. Hysteresis performance under sinusoidal excitation.

The describing function $N\left(\theta_{m}\right)$ of the nonlinear system with hysteresis [14] is described in (2).

$$
\begin{aligned}
N\left(\theta_{m}\right)= & \frac{k}{\pi}\left[\frac{\pi}{2}+\sin ^{-1}\left(1-\frac{2 \delta}{\theta_{m}}\right)+\left(1-\frac{2 \delta}{\theta_{m}}\right) \sqrt{1-\left(1-\frac{2 \delta}{\theta_{m}}\right)^{2}}\right] \\
& +\mathrm{j} \frac{4 k}{\pi} \frac{\delta}{\theta_{m}}\left(\frac{\delta}{\theta_{m}}-1\right)
\end{aligned}
$$

\section{B. Identification method based on describing function method}

Based on the describing function method, the output fundamental wave of the nonlinear system with sinusoidal excitation is approximated to represent the system response. The backlash identification equation can be derived according to the relationship between the phase angle of the system's describing function and the lagging phase $\varphi$ of output fundamental wave, as illustrated in (3).

$$
\operatorname{tg}^{-1}\left(\frac{\frac{4 \delta}{\theta_{m}}\left(\frac{\delta}{\theta_{m}}-1\right)}{\frac{\pi}{2}+\sin ^{-1}\left(1-2 \frac{\delta}{\theta_{m}}\right)+\left(1-2 \frac{\delta}{\theta_{m}}\right) \sqrt{1-\left(1-2 \frac{\delta}{\theta_{m}}\right)^{2}}}\right)=\varphi
$$

Using Fourier Transform for input and output signals, the lagging phase $\varphi$ can be extracted, then the backlash angle $2 \delta$ can be calculated based on the amplitude of excitation $\theta_{m}$ and the backlash identification equation. It needs to be pointed out that (3) is a strong nonlinear equation, which is difficult to solve by general methods, this paper adopts the least square method to fitting the curve of (3), the approximation between backlash angle $2 \delta$ and the lagging phase $\varphi$ can be obtained. Numerical simulation shows that the errors of this method is very small, less than $10^{-6}$.

Under excitation with large amplitude and frequency, the gear transmission mechanism with backlash shows obvious dynamic characteristics, the impact and collision phenomena between the teeth of drive and driven gears are significant and the delay between the rotation angle of drive and driven gears is no longer constant but time varying, therefore, the system responses are different from the hysteresis model. Appropriate sinusoidal signal is selected by lowering the amplitude $\theta_{m}$ and frequency $\omega$ of the excitation, it can reduce the dynamic effects of the transmission process and considerably narrow the differences between the system responses and the hysteresis model, thus, make full use of the relationship between lag phase and backlash size in the quasi-static transmission and increase the identification precision.

\section{SimUlation AND DiscUSSION}

The ADAMS model of gear transmission with backlash is shown in Fig. 3, includes drive and driven gears. The gear ratio is $1: 1$, the base circle radius of drive and driven gears equal $80 \mathrm{~mm}$, the friction coefficient of driven gear bearing equals 0.001 . The center distance deviation of drive and driven gear is $5 \mathrm{~mm}$, the backlash angle is measured and used as identification standard, which equals $0.050924 \mathrm{rad}$. 


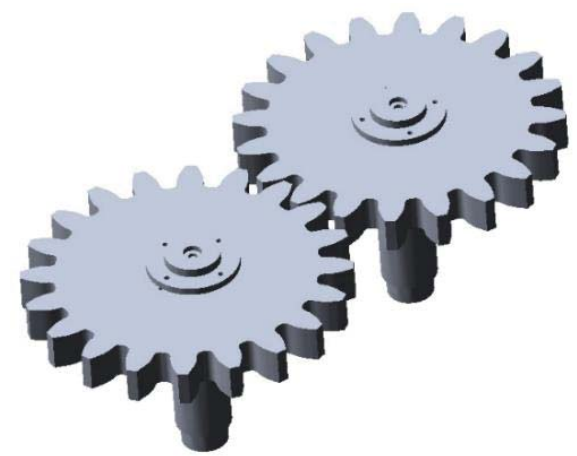

Fig. 3. ADAMS model of gear transmission with backlash.

In the method proposed in this paper, the lagging phase of output fundamental wave for backlash identification is extracted based on the input and output signals in the complete running cycle. As a comparison, an identification strategy based on the break of transmission torque in the contactseparation-contact process is established, to analyze the identification accuracy differences between the method based on the system response in the complete running cycle and the method based on the system response in the contact-separationcontact process. As illustrated in (1), when $t=\frac{\pi-\beta}{\omega}$, the tooth of drive gear collides with the tooth of the driven gear, which will cause obvious transmission torque mutation, $\beta=\pi-\omega t$ can be derived from the moment of the transmission moment mutation, then according to $\beta=\sin ^{-1}\left(\frac{\theta_{m}-2 \delta}{\theta_{m}}\right)$, the backlash angle can be identified by $2 \delta=\theta_{m}(1-\sin (\pi-\omega t))$.

Three sets of excitations are used to analyze the influence of different excitation amplitude and frequency on the identification precision, as shown in Table I.

TABLE I. AMPLITUDES AND FREQUENCY OF THREE SETS OF EXCITATIONS

\begin{tabular}{|c|c|c|c|}
\hline & Load $\boldsymbol{A}$ & Load $\boldsymbol{B}$ & Load $\boldsymbol{C}$ \\
\hline Amplitude $(\boldsymbol{O})$ & 30 & 10 & 30 \\
\hline Frequency $(\mathrm{Hz})$ & $2 \pi / 30$ & $2 \pi / 30$ & $2 \pi / 60$ \\
\hline
\end{tabular}

Fig. 4 is a time history diagram of the rotation angles of drive and driven gears under different loads, which illustrates an relatively regular lag angle between the rotation angle of drive and driven gears, it also can be seen that the lag angles of load $\mathrm{B}$ and $\mathrm{C}$ are more obvious.

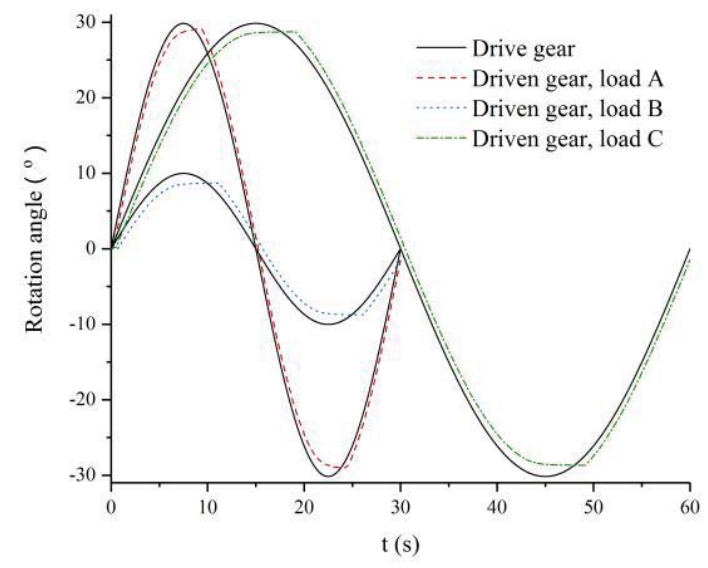

Fig. 4. System responses under excitations with different amplitudes and frequencies.

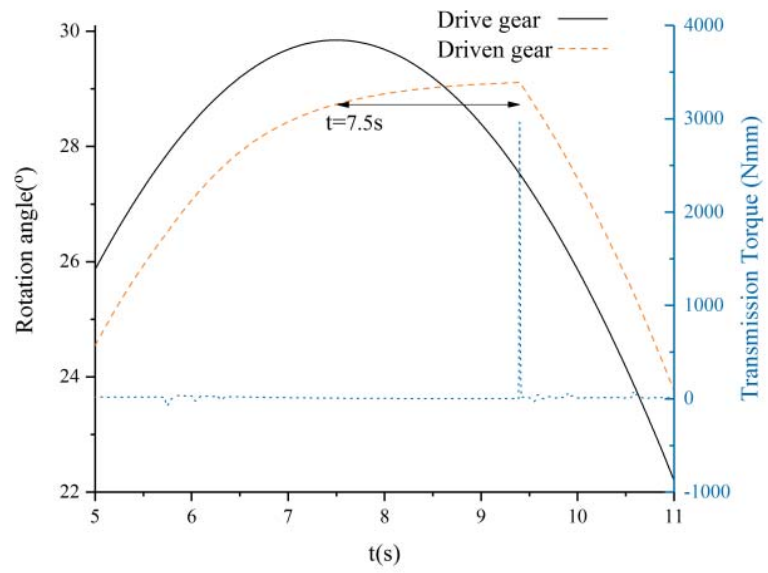

Fig. 5. Contact-separation-contact process under load A.

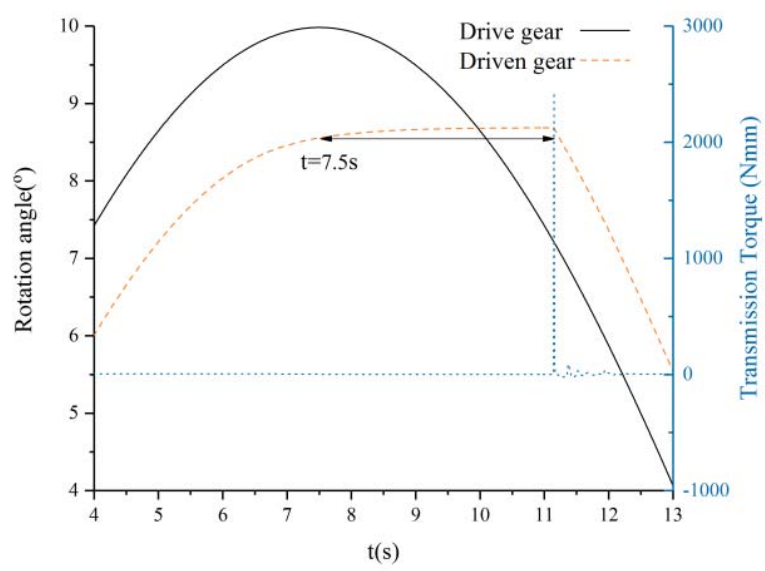

Fig. 6. Contact-separation-contact process under load B. 
TABLE II. IDENTIFICATION RESULTS OF GEAR BACKLASH

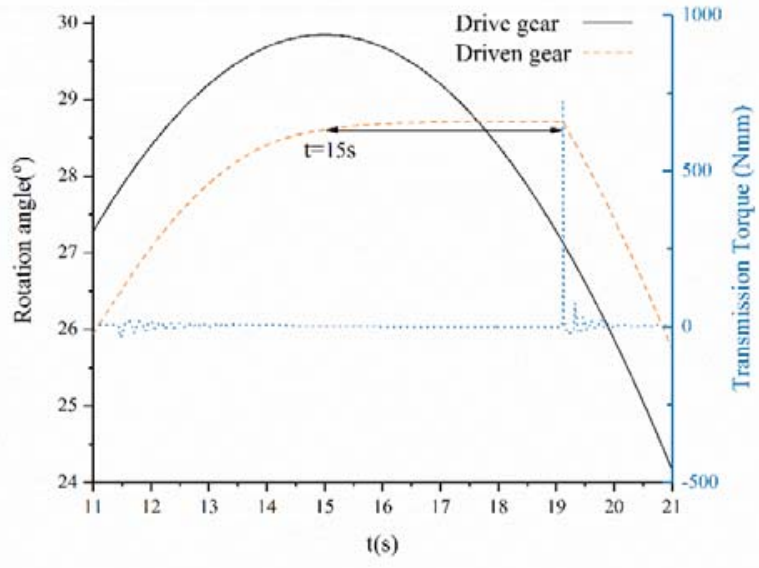

Fig. 7. Contact-separation-contact process under load C.

Figs. 5-7 demonstrate the contact-separation-contact processes under load A, B and $\mathrm{C}$ respectively. As shown in Fig. 5 , the drive and driven gear separate from each other as $t=7.5 \mathrm{~s}$ hence the drive gear start to change rotation direction, then it moves within backlash, the driven gear is no longer driven by drive gear and its rotation speed decays under friction force. However, the amplitude and frequency of load A are relatively high and result in relatively large speed of the driven gear. At the moment of $\mathrm{t}=9.4 \mathrm{~s}$, the drive gear comes into contact with the driven gear on the back side, large relative speed causes violent collision and the mutation of transmission torque. The hysteresis model assumes that the position of driven gear keep constant during the contact-separation-contact process. It can be seen from the analysis that the system responses in the contact-separation-contact process are deviated from the hysteresis model under load A and the decay of the rotation speed of driven gear is not obvious.

Compared to load A, the difference between the system responses under load $\mathrm{B}$ and the hysteresis model become smaller, as illustrated in Fig. 6. The drive gear comes out of contact with the driven gear at $t=7.5 \mathrm{~s}$, the position of driven gear is not constant in the contact-separation-contact process, however, the speed of driven gear is relatively small, at $\mathrm{t}=$ $11.15 \mathrm{~s}$ the drive gear comes into contact with the driven gear and the collision becomes slight owing to the low excitation amplitude of load B.

Fig. 7 shows the time history of the system responses under load C. It can be observed that the appearance of the collision and the difference between the system responses and the hysteresis model are slighter than which of load A. As illustrated in Fig. 7, the drive gear separates from the driven gear at $\mathrm{t}=15.0 \mathrm{~s}$ and comes into contact with the driven gear as $\mathrm{t}=19.12 \mathrm{~s}$, the driven gear is nearly static during this time.

Table II shows the results which are identified by the method based on the describing function and the method based on the break of transmission torque respectively.

\begin{tabular}{|l|c|c|c|c|}
\hline & $\begin{array}{c}\text { Based on the } \\
\text { break of } \\
\text { transmission } \\
\text { torque }\end{array}$ & $\begin{array}{c}\text { Relative } \\
\text { errors }\end{array}$ & $\begin{array}{c}\text { Based on the } \\
\text { describing } \\
\text { function }\end{array}$ & $\begin{array}{c}\text { Relative } \\
\text { errors }\end{array}$ \\
\hline Load $\boldsymbol{A}$ & 0.040912 & $19.66 \%$ & 0.051616 & $1.36 \%$ \\
\hline Load B & 0.048562 & $4.64 \%$ & 0.051326 & $0.79 \%$ \\
\hline Load $\boldsymbol{C}$ & 0.047981 & $5.78 \%$ & 0.051186 & $0.51 \%$ \\
\hline
\end{tabular}

As illustrated in Table I, the amplitude of load B is one third of that of load A and the frequency of load C is one half of that of load A. It can be seen from the Table II that the larger the excitation amplitude and frequency are, the smaller the identification accuracy is, due to the differences between the system responses and the hysteresis model become slighter under lower excitation amplitude and frequency. The algorithm based on the break of transmission torque identifies the backlash parameter through the system responses in the contact-separation-contact process. Its identification precision is significantly lower than that of the method which identifies the backlash through the system responses in the complete running cycle, owing to the delay between the rotating angle of drive and driven gears keeping constant as the gears engaged, the system responses are in good agreement with the hysteresis model during this process.

As to the identification accuracy of the method proposed based on the describing function, the accuracies belong to load $\mathrm{A}, \mathrm{B}$ and $\mathrm{C}$ are $1.36 \%, 0.79 \%, 0.51 \%$ respectively. The durations of the contact-separation-contact processes belongs to load $\mathrm{A}, \mathrm{B}$ and $\mathrm{C}$ are $1.9 \mathrm{~s}, 3.65 \mathrm{~s}, 4.12 \mathrm{~s}$ respectively. The ratios of these processes to the total processes are 1.9/30, $3.65 / 30,4.12 / 60$ respectively, the ratio belongs to load $\mathrm{C}$ is smallest. According to the dates mentioned above, we can find that lowering the frequency not only diminishes the deviation between the system responses and the hysteresis model, but also decreases the ratio of the contact-separation-contact process to the total process, thus reduces the influence of the deviation on identification precision. Hence, it can be concluded that compared to decreasing the amplitude, lowering the frequency can promote the identification accuracy more effectively.

\section{CONCLUSIONS}

A new method is developed based on hysteresis backlash model and describing function method for backlash identification. A sinusoidal excitation with appropriate amplitude and frequency is utilized as the system input, which can reduces the impact and collision between meshing teeth and enhances the hysteresis effect. Fundamental components from the system output digitals are extracted through Discrete Fourier Transform. On the basis of the relationship between the phase angle of describing function and that of the fundamental components, the backlash parameter can be identified accurately. A gear transmission with backlash is considered as a numerical example, simulation results reveal this method can achieve precise identification of backlash. Numerical results of multi-group excitations reveal that the selection of amplitude and frequency of excitation is significant to the accuracy of the identification method, and lowering the frequency can promote the identification accuracy more effectively. 


\section{ACKNOWLEDGMENTS}

This research was supported by the National Natural Science Foundation of China under Grant No. 11702294 and the Key Project of Chinese National Programs for Fundamental Research and Development (973 program) under Grant No.2013CB733000.

\section{REFERENCES}

[1] M. Nordin, P.O. Gutman, "Controlling mechanical systems with backlash-a survey", Automatica, vol.38, issue 10, pp.1633-1649, 2002.

[2] O.I. Elgerd, "A study of asynchronously excited oscillations in nonlinear control systems", IRE Transaction on Automatic Control, vol.5, issue1, pp.183-185, 1960.

[3] P. Rostalski, T. Besselmann, M. Baric, F.V. Belzen, M. Morari, "A hybrid approach to modeling, control and state estimation of mechanical systems with Backlash", International Journal of Control, vol.80, issue 1, pp.1729-1740, 2007

[4] J.H. Taylor, J. Lu, "Robust nonlinear control system synthesis method for electro-mechanical pointing system with flexible modes", Journal of systems Engineering, vol.5, pp.192-204, 1995.

[5] G.F. Zhao, W.H. Fan, Q.W. Chen, W.L. Hu, "A Survey on Backlash Nonlinearity", Acta armametarii, vol.27, issue 6, pp.1072-1080, 2006.(in Chinese
[6] T. Tjahjowidodo, F. Al-bender, B.H. Van, "Experimental dynamic identification of backlash using skeleton methods", Mechanical Systems and Signal Processing, vol.21, issue 2, pp.959-972, 2007.

[7] M. Nordin, P. Bodin, P.O. Gutman, Adaptive Control of Nonsmooth Dynamic Systems: New models and identification methods for backlash and gear play, London, Springer London, pp.1-30, 2001.

[8] A. Lageerberg, B. Egardt, "Backlash estimation with application to automotive powertrains", IEEE transactions on Control Systems Technology, vol.15, issue 3, pp.483-493, 2007.

[9] F. Mazzini, S. Dubowsky, "The tactile exploration of a harsh environment by a manipulator with joint backlash", ASME 2010 International Design Engineering Technical Conferences and Computers and Information in Engineering Conference, Montreal, Quebec, Canada, pp.1399-1407, 2010

[10] E. Bai, "Identification of linear systems with hard input nonlinearities of known structure", Automatica, vol.38, issue 5, pp.853-860, 2002

[11] Y.S. Tarng, J.Y. Kao, Y.S. Lin, "Identification of and compensation for backlash on the contouring accuracy of CNC machining centers", The International Journal of Advanced Manufacturing Technology, vol.13, issue 2, pp.77-85, 1997.

[12] K. Ogata, Modern Control Engineering, Prentice-Hall, Englewood Cliffs, New Jersey, pp.559-561, 1970

[13] J.E. Jean, W. Li, Applied Nonlinear Control, Prentice-Hall, Englewood Cliffs, New Jersey, pp.177-179, 1991.

[14] A. Gelb, W.E. Vander, Multiple-input Describing Functions and Nonlinear System Design, McGraw Hill, pp.67-71, 1968 